\title{
Using Knowledge Space Theory to Delineate Critical Learning Paths in Calculus
}

\author{
Iman C Chahine \\ SDL Research Unit- North West University \\ Potchefstroom, South Africa \\ University of Massachusetts Lowell \\ Massachusetts, USA \\ Mark Grinshpon \\ Georgia State University \\ Georgia, USA
}

\begin{abstract}
This study examined the effects of using tutorials in precalculus content on college students' performance in Calculus 1 as measured by the levels of conceptual development delineated through critical learning paths based on their achievement scores and quizzes. Our main objective is to provide evidence that a strong grounding in pre-calculus concepts is necessary for students' success in Calculus and beyond. We employed Knowledge Space Theory (KST) to analyze data collected on a set of calculus questions that reflect different levels of conceptual development. These calculus questions were given to a group of students enrolled in calculus classes at a Southeastern urban university in the United States. Three tests were examined and the knowledge states were extracted for each test (using Visual Basic software) and knowledge trees were constructed (using an $\mathrm{R}$ package) to determine students' critical learning paths. The findings of this study revealed that critical learning paths supported evidence that a strong foundation in Precalculus is necessary for students' success in Calculus and beyond. Juxtaposing the succession of knowledge states and critical learning paths reflected student understanding of the basic calculus concepts and proposed a systematic approach to supplemental enrichment and remediation.
\end{abstract}

Keywords: Knowledge space theory; Precalculus; Calculus teaching; Critical learning paths; Problem-based learning

\section{Introduction}

As undergraduate students continue to struggle in calculus courses, the mainstream belief that these courses act as gatekeepers preventing students from majoring in STEM fields is further confirmed. According to a study conducted 
by the Mathematical Association of America (MAA), about $47 \%$ of students received a D or better in Calculus I (Ganter \& Haver, 2011). The other 53\% either failed the course or dropped the class. This high "failure" rate raised serious concerns among educators and mathematicians. Such concerns are exacerbated for women as typically they are twice less likely to continue beyond Calculus I, even when Calculus II is a requirement for their intended majors (Bressoud et al., 2013). Not surprisingly, Freeman et al. (2014) argue that the majority of failing grades occur in classes that use the more traditional lecture method of teaching rather than student-centered approaches. To compensate for the dismal success rate in calculus, the National Science Foundation (NSF) supported grants that addressed the undergraduate calculus curriculum and failure rate (Ganter, 2001). These grants created a nationwide effort to reform the way calculus was taught at the undergraduate level. While reform methods for teaching calculus differed across the nation, some common themes emerged. Cooperative grouping, writing, and effective use of technology were found to be very effective in curbing the high failure rate in calculus courses amongst undergraduates (Pilgrim, 2010).

With the increased funding and research being poured into calculus studies, one would think that the national failure rate would be tremendously lower now than in the mid-eighties or nineties. However, current data suggest the opposite. Pilgrim (2010) and Reinholz (2009) both agree that the national failure rate, a D or F, for students initially enrolled in Calculus I is about $40 \%$. Once most programs of study require a letter grade of $\mathrm{C}$ or higher, grades of $\mathrm{D}$ and $\mathrm{F}$ would both be considered failing. A true comparison cannot be made between the mideighties and today and the true cost of the national failure rate in calculus remains difficult to calculate. Is failing first-year calculus causing students to change majors? Drop out of planned careers? Or even shorten their college careers altogether by withdrawing from school?

According to the US National Center for Education Statistics (NCES), of all the bachelor's degrees awarded in 2009, only $16 \%$ were in mathematics, computer science, physical sciences, and engineering (Snyder \& Dillow, 2010). The latest data shows that women earned $60 \%$ to $62 \%$ of all associate's degrees awarded between 2000 and 2015 (National Science Foundation (NSF), 2018). The proportion of women earning science and engineering associate's degrees, however, declined from $48 \%$ in 2000 to $44 \%$ in 2015. Most of the decline is attributed to a decrease in women's share of computer sciences associate's degrees, which dropped continuously from $42 \%$ in 2000 to $21 \%$ in 2015 (National Science Board, 2018a \&b).

In contrast to the declining college success of students in Calculus I, high school enrollment in Precalculus, Advanced Calculus, and dual enrollment has never been higher. A 2015 report of the National Center for Educational Sciences (Kena et al., 2015) showed that about $15 \%$ of ninth-graders typically earn at least some high school credit in calculus; while about $9 \%$ of students could reach Algebra I or less. Moreover, about 37\% of fall 2009 ninth-graders had earned high school credit in an AP or IB course by 2013, and 15\% had earned AP or IB credit in 
math, while $14 \%$ had earned such credit in science. With more high school students taking calculus courses in high school, why does the failure rate at the college continue to increase?

Extensive literature has provided numerous recommendations on the usefulness of calculus and the promising ways to increase the percentage of students passing calculus classes. Berkaliev and Kloosterman (2009) explained that students' perception of their chances to obtain a passing grade of $\mathrm{C}$ or higher either helps or impedes the learning of mathematics. In another vein, and according to Bishop-Clark et al. (2010), dual enrolment can change the attitudes and readiness of high school students for college mathematics. The authors found that students who were enrolled in career technical education programs at the high school level were significantly more likely to "graduate, more likely to enroll in college, more likely to enroll in a four-year college, and more likely to progress faster in post-secondary degrees" (p. 90). Students' beliefs and attitudes towards mathematics can also affect how they choose to approach mathematical problems (Bonne \& Johnston, 2016). If students do not have an understanding of the usefulness of the mathematics courses in facilitating future career choices, then student motivation and time spent on solving mathematics problems will likely decline. Likewise, Rajagukguk (2016) showed that students who have a positive attitude towards learning calculus are more likely to have a higher success rate in Calculus than those who do not. Therefore, a common assumption held by those that research student attitudes toward mathematics is that there is a relationship between attitude and academic achievement.

Currently in calculus research, there are several common interventions that researchers have found to decrease the failure rate in post-secondary calculus. These include writing about calculus concepts and technology (Kay \& Kletskin (2010), hands-on explorations (Klymchuk \& Zverkova, 2010), higher-level questioning and cooperative learning groups (Cardetti \& McKenna, 2011). When these interventions were implemented, students succeeded at a higher level than students in a traditional calculus course taught through instructor-driven lectures. For example, Karaali (2011) found that students were able to think critically when asked to write about why they were taking calculus and what they were getting out of it. Based on Bloom's Taxonomy, the researcher noted that students purposefully engaged in writing activities that required performance at the highest level of the taxonomy, namely evaluation. Toward the end of the course, Karaali (2011) had the students evaluate their contribution to the course by allowing the students to write as "coherently as possible" and this "created a more reflective, more conscious, and thus a more effective learning experience for all involved" (p.732).

In another research, Klymchuk et al. (2010) conducted a parallel study at two different universities, one in Germany and the other in New Zealand. The study examined engineering students' difficulties in "the formulation steps of solving a typical application problem from a first-year calculus course" (p. 81). Klymchuk et al. (2010) explained that common application problems tend to be long and mathematized. The authors noted that, while students were not 
required to collect or analyze data to make assumptions, in many application problems they still "have to go through the formulation step of the mathematical modeling process that often requires choosing/constructing a formula or setting up a function for further investigation" (p. 81). The findings of this study provided evidence that calculus courses need to reinforce basic skills in solving application problems early on and that writing the steps in detail help students solve real-life problems that require mathematical modeling skills in other classes and their future careers (Crouch \& Haines, 2004).

The second common area in calculus research is technology. Different forms of technology have long been implemented in the undergraduate learning environment. For example, utilizing the TI 84 and higher calculators has become standard in most classrooms. Naidoo and Naidoo (2007) found that when students in their undergraduate classes used the computer to perform tasks for "their compulsory project (they) had the advantage of using constructive interactive methods and cooperative learning strategies to aid their understanding of concepts" (p. 62). The blended method of teaching helped offset the large class sizes and the weak preparation by the students. The students also felt that the computers helped with the "disinterest in the subject" (p. 55). In a similar vein, Kay and Kletskin (2010) explained that the students who used online mini-clips felt that they were more prepared for class and used the mini-clips "to review past lessons and examples" (p. 103). Some of the features that undergraduate calculus students found useful about the mini-clips were the ease with which they could follow the lessons, the clear explanations, and the freedom to view the clips on their own time. It is worth mentioning though that, when incorporating the computer into any classroom setting, computer software design is important. If the programs are too advanced for the learner, then the result could be the same as having a lecturer at the front of the room while a class full of undergraduates sit and wonder when they should drop the class.

The third common area of research that has been conducted in calculus classes is the cooperative learning groups. In this context, Cardetti and McKenna (2011) argued that several different factors motivate undergraduate students to engage in cooperative learning environments. Intrinsic satisfaction, competition and the formation of sharing groups are three important incentives the researchers cited to increase undergraduate students' mathematics scores.

While improving STEM (Science, Technology, Engineering, and Mathematics) education in the United States has been a critical national concern, the pipeline of students entering STEM does not meet the current demand for future scientists and engineers. One of the reasons identified for this attrition has been students' underperformance in calculus classes and their inadequate preparation in Precalculus content. Hence, addressing this national need requires research and development of the best pathways to remediate the teaching of Precalculus and calculus concepts, which would translate into efficient models of providing support to students in learning the content. 
In this study, we examined the effects of using tutorials in pre-calculus content on students' performance in Calculus 1 as measured by the levels of conceptual development delineated through critical learning paths. Performance is reflected in their achievement scores and quizzes. Using Knowledge Space Theory (KST) approaches our main objective is to provide evidence that a strong grounding in pre-calculus concepts is necessary for students' success in Calculus and beyond. Specifically, the study addresses the following question: What is the effect of using tutoring of pre-calculus concepts/content on students' achievement in calculus as measured by the levels of conceptual development delineated through KST critical learning paths?

\section{Knowledge Space Theory: A Framework to Evaluate Student Knowledge}

Admittedly, assessing students' conceptual understanding of mathematics, particularly at the college level, can be a daunting task. With many different methods to evaluate performance, it is hard to know which are effective, considering the depth and breadth of knowledge that students are required to master. Principled by a structural analysis of responses to assessment tools, Knowledge Space Theory (KST) is a formal method or model for representing students' knowledge in a given context (Sanghoon, Belkasim, Chahine, \& Grinshpon, 2014). The structure created provides details related to students' knowledge and the learning paths taken to acquire that knowledge. As an assessment procedure, KST can inform the instructor of the order in which a group of students are mastering different concepts given during instructional periods. Falmagne et al. (1990) and Doignon and Falmagne (2015) introduced KST as a "means to formally describe the structure of a given domain of knowledge" (p. 201). Broadly, the structure is depicted through the problems that students can answer correctly. Students' responses on a given assignment or test become a subset of the overall structure and a learning path can be traced from the null set of problems attempted (none correct) to the complete set (all correct).

By the same token, Arasasingham et al. (2005) employed KST to assess learning in chemistry at two different universities. They found that "secondary students leave high school with significant deficiencies in their understanding of basic chemical principals" (p. 1522). Their KST analysis showed that students' logical framework of understanding basic chemistry was very weak. Their analysis revealed that while students may know basic factual information, they were not able to transfer and utilize this knowledge to solve conceptual problems. The researchers connected these problems to the teaching methods at the high school level and the textbooks used. They further indicated that students' inability to connect factual information and conceptual problems "was not surprising since the information students use to construct their knowledge comes from either texts or instruction, both of which tend to present the material in this manner" (Arasasingham et al., 2005, p.1522). Arasasingham et al. further explained that KST "is a useful tool for revealing various aspects of students' cognitive structure" (p. 1522) and that not only can KST be used as an assessment tool but 
also as "a pedagogical tool to address a number of student learning issues" (p. 1523). As an assessment tool, KST has the potential to monitor the development of students' conceptual understanding of the taught concepts. Moreover, with its facility to delineate learning trajectories, KST can also gauge how well students can use the concepts taught and utilize them in solving problems across situations. According to Arasasingham et al. (2005), not only can KST help analyze the nature of the knowledge that students bring to a course, but it can "assess whether students have conceptualized the content as intended after the conclusion of the course" (p. 1523).

Besides chemistry and mathematics, KST has been employed to identify learning pathways in many different settings, such as comparing textbook assigned homework versus online homework (Arasasingham et al, 2005), and finding the best model to teach the concept of describing an ion (Tóth \& Ludányi, 2007). According to Steiner et al. (2009), KST can also be blended to integrate two teaching pedagogies, namely self-regulated learning and competence-based enhanced online learning. KST has also been adapted to aid in assessing the clinical responses of an in-depth psychological assessment (Spoto et al., 2010).

Generally, in the KST framework, a field of knowledge is specified by a finite set of items. This set consists of the problems or questions that a student may or may not be able to solve on a given assessment (Sanghoon, Belkasim, Chahine, \& Grinshpon, 2014). Each student can be described by his/her knowledge state, which is the subset that is created by the number of problems or questions they answered correctly (Doignon \& Falmagne, 2015). After each member of the class has a subset or their knowledge state-determined, the subsets are combined to create the field of knowledge. The field of knowledge shows the learning paths that the entire group took to maneuver from the null set $\varnothing$ (all responses incorrect) to the complete set $\mathrm{Q}$ (all responses correct).

It is worth mentioning that the learning paths do not necessarily follow the assessment questions in chronological order. For example, if the learning path for five questions was 1-3-2-5-4 then it can be said that before question two can be answered correctly, question three must be mastered. It is important to note that not all possible subsets of items are knowledge states since a prerequisite relationship between the assessment items could exist. The set of all possible knowledge states is called a knowledge space.

The method to select these states is an orderly trial and error process using the $\chi^{2}$ analysis. Chi-Square statistic $\left(\chi^{2}\right)$ is based on the difference between the actual response states and the expected knowledge states. To begin, the most populated response states are added and subtracted to minimize the $X^{2}$ value, forming an interconnected network where each state (other than $\emptyset$ and Q) has a preceding state and a succeeding state. Each successive state has exactly one more question than the preceding one. At first, many of the largely populated response states are combined with other possible response states to form a provisional knowledge structure that is then modified by the addition and subtraction of states in an evolution toward a final knowledge structure with its 
minimum $\chi^{2}$ value. The $\chi^{2}$ calculation indicates how well the selected states represent the original data set. The resulting knowledge structure can reveal several learning pathways that students use to learn. Stahl and Hockemeyer (2019) defined a learning path as "a maximal sequence of knowledge states, which allows learners to gradually traverse a knowledge structure or space from the empty set $(\varnothing)$ (or any other bottom state) to the full set of domain problems $Q^{\prime \prime}$ (p.9). Beginning at the empty set $(\varnothing)$, to full mastery state $(Q)$ the learning pathways can be mapped out.

Once the knowledge structure has been created, the approximate probability value for each knowledge state is found from the $\chi^{2}$ fit. The probability value for each knowledge state represents the portion of students in the classes who are in the knowledge state. From the largest probability knowledge states, the best or most probable learning pathway is identified as the critical learning pathway consisting of response states, which best define the class. If some of the most populated responses do not appear on the critical learning pathway, that means that getting that sequence of questions correct on the test does not necessarily mean that there is not a logical framework or true comprehension of the material. Once the critical pathway is established, it is then possible to compare each student to the general class performance as well as to the top performers (the Q set).

\section{Study Methods}

\section{Participants}

The participants in this research study were students enrolled in the Calculus I course. This is a 4-credit course required for the university's undergraduate students majoring in Mathematics, Statistics, Physics, Chemistry, Computer Science, Actuarial Science, and Geology. Many students from other majors also take this class, most notably Biology majors (on average approximately $25-30 \%$ of the total number of students enrolled in Calculus I) on the pre-med track. A typical enrollment in one section of Calculus I is 40-47 students, and there are usually 8-10 sections of the course each semester.

At the beginning of the study, two sections of Calculus I taught by the same instructor were chosen and randomly assigned as the experimental and the comparison group. Early in the semester, students were given a "Prerequisite Skills Check" - a quiz consisting of 24 basic Precalculus problems, each involving a Precalculus concept or skill that is necessary for calculus; the same quiz was administered at the end of the semester. The pre-quiz measures the incoming students' baseline knowledge of Precalculus, hence a comparison between the pre and post quiz results measured the change in that knowledge.

Throughout the semester both sections completed their regular coursework, which includes practice homework, 10-15 online graded quizzes, in-class tests, and a comprehensive final exam - all testing the calculus material taught in class. The experimental group (hereafter the TUTORING group) was also offered scheduled tutoring sessions with a teaching assistant. Students were 
continuously encouraged to attend these sessions, which were student-centered, and focused on individualized tutoring tailored to specific students' needs with emphasis on Precalculus problem-solving skills (See Table 1).

Table 1. A list of Precalculus tutoring topics

\begin{tabular}{|l|l|}
\hline Week & Precalculus Topic \\
\hline One & Properties of exponents \\
\hline Two & Simplifying rational expressions \\
\hline Three & Roots and radicals \\
\hline Four & Trigonometric functions and the unit circle \\
\hline Five & Composition of functions \\
\hline Six & Unit Circle \\
\hline Seven & Review of elementary functions. \\
\hline Eight & Solving algebraic inequalities \\
\hline Nine & Solving trigonometric equations and inequalities. \\
\hline Ten & Graphs of functions \\
\hline Eleven & Area under the graph \\
\hline Twelve & The laws of limits \\
\hline Thirteen & Limits of functions \\
\hline
\end{tabular}

The tests were graded by a group of Graduate Teaching Assistant (GTA) graders, each working with a particular instructor. They were also responsible for the weekly homework assessments, which consisted of just three or four questions. Weekly meetings were held for the homework graders to ensure consistency of scoring. The meetings were designed to preview the following week's homework, point out potential pitfalls, and allow graders to share how they graded the previous week's questions. The weekly meetings were led by one of the instructing faculty members, allowing graders to see first-hand examples of what the faculty was expecting. The leading faculty member consistently gave several possible methods to obtain the correct response to the assessment questions and the graders were also asked to prepare potential solutions to the following week's assessment questions. This arrangement kept instructors and graders engaged and informed of the direction that the calculus homework grading was taking.

\section{Procedure and Data Collection}

We used three instruments to collect data: 1) tutoring observation logs, 2) calculus tests and final exam, and 3) pre and post Precalculus Skills Check quizzes. Some problem items in the regular tests were specifically redesigned as multiple part questions to obtain separate numerical scores on both Calculus and Precalculus aspects. Tests were graded by a set of graders who worked with each instructor exclusively and were also responsible for the weekly homework assessments, which consisted of just three or four questions.

Weekly meetings were led by one of the instructing faculty members, allowing the graders to see, first-hand, the level of performance that the faculty was expecting. The leading faculty member consistently shared several possible 
methods to obtain the correct response to assessment questions and graders were also encouraged to produce possible solutions to the following week's assessment questions. Engaging the graders to co-create grading schemes with faculty was necessary to clarify the expectations for grading calculus homework and to ensure consistency of scoring. The meetings were designed to preview the following week's homework, point out potential pitfalls, and allow the graders to share how they graded the previous week's questions.

\section{Data Analysis using KST}

We employed knowledge Space Theory (KST) (Falmagne et al, 1990; Arasasingham et al., 2005) to analyze and extract critical learning paths to assess performance in two calculus classes: experimental and comparison class. The experimental calculus course included requisite Precalculus concepts taught in a constructivist manner, using problem-based learning that is less restrictive than the traditional calculus course, which typically involves students sitting quietly while an instructor lectures. We hypothesized that incorporating Precalculus concepts using multiple representations and through cooperative learning techniques in the experimental calculus class could create a learning environment more supportive of meaningful learning. Such an assertion is supported by our belief that calculus cannot be learned through watching and listening - it is learned by doing. Using data collected from both groups of students and analyzing questions reflecting different levels of conceptual development allowed us to determine the critical learning paths of students in the Calculus class.

Three tests were examined and the knowledge states were obtained for each (using visual basic software) and knowledge trees were constructed (using an $\mathrm{R}$ package) to determine these critical paths. We hypothesized that concepts acquired by students include: solving algebraic inequalities (Pre-calculus), finding the velocity and the acceleration as derivatives (Calculus), sketching two graphs and the region between them and finding their points of intersections (Pre-calculus), finding an anti-derivative (Calculus), evaluating anti-derivatives (Pre-calculus), and integrating to find the area (Calculus).

Using (KST), we were able to map students' knowledge structure on solving precalculus problems which depicts students' knowledge structure and state at different levels of the intervention. For example, we were able to monitor students' initial knowledge upon entering the class and assess the additional knowledge states that students acquired as a result of explorations and intervention. Based on this knowledge structure, we were able to detect the critical learning pathways during course assessments. In the next section, we discuss in detail the process of examining student knowledge based on KST approaches.

To process the data, we utilized Potter's Visual Basic code, which converted the response structure into knowledge structure and allowed the detection of the critical learning pathways. The raw data from the test results were obtained and the highest point (completely correct answer) of each question was coded as ' 1 ' 
and the points lower than the highest point (correct or partially correct) was defined as '0.' Table 2 shows data entered into a text file as the input file.

Table 2. Coded test results data

$$
\begin{aligned}
& \hline 111101111,1 \\
& 111101011,1 \\
& 111100101,1 \\
& 1101101101,1 \\
& 1101101100,1 \\
& 1100011110,1 \\
& 1011100000,1 \\
& 1001111100,1 \\
& 1001101101,1 \\
& 1001100011,1 \\
& 1001100000,2 \\
& 1001001110,1 \\
& 1000100000,1 \\
& 1000001101,1 \\
& 0111101100,1 \\
& 0101111111,1 \\
& 0101111101,1 \\
& 0011101001,1 \\
& 0011100000,1 \\
& 0010001100,1 \\
& 0010000111,1 \\
& 0001101100,1 \\
& 0001100010,1
\end{aligned}
$$

As indicated in Table 2, the first column before the comma represents the knowledge states for each student on questions 1 to 10 , with ' 1 ' representing a correct answer and ' 0 ' representing an incorrect (partially or fully) answer. The second column right after the comma indicates the number of students at the same response state. In the case of Test 1 for the comparison group, there were 31 knowledge response states. The rows after the 31st row are the knowledge states of assumed/expected knowledge structure, which have a 0 right after the comma for each row (see Table 3). 
Table 3. Knowledge states for Test 1

\begin{tabular}{|l|}
\hline 0010000000,0 \\
0000100000,0 \\
0000000010,0 \\
0000000001,0 \\
1001000000,0 \\
1010000000,0 \\
1000100000,0 \\
1000000010,0 \\
0010100000,0 \\
0010000010,0 \\
1000000001,0 \\
1011000000,0 \\
0011100000,0 \\
1010100000,0 \\
0001100010,0 \\
0011000010,0 \\
0010001100,0 \\
0001100001,0 \\
1011100000,0 \\
0011100010,0 \\
1010100010,0 \\
1001100010,0 \\
1000001101,0 \\
1001001100,0 \\
1011100010,0 \\
1001100011,0 \\
\hline
\end{tabular}

Copying this text file into Potter's Visual Basic program allowed us to automatically generate the output file. Before running this program, however, we checked the directories of input and output files, the number of questions, the number of students, and the number of responses and assumed responses in the file. The Visual Basic code that was used in this case already had an estimated $10 \%$ probability for both lucky-guess and careless errors. After running the program, we obtained the output file in Table 4. 
Table 4. Output file for Test 1

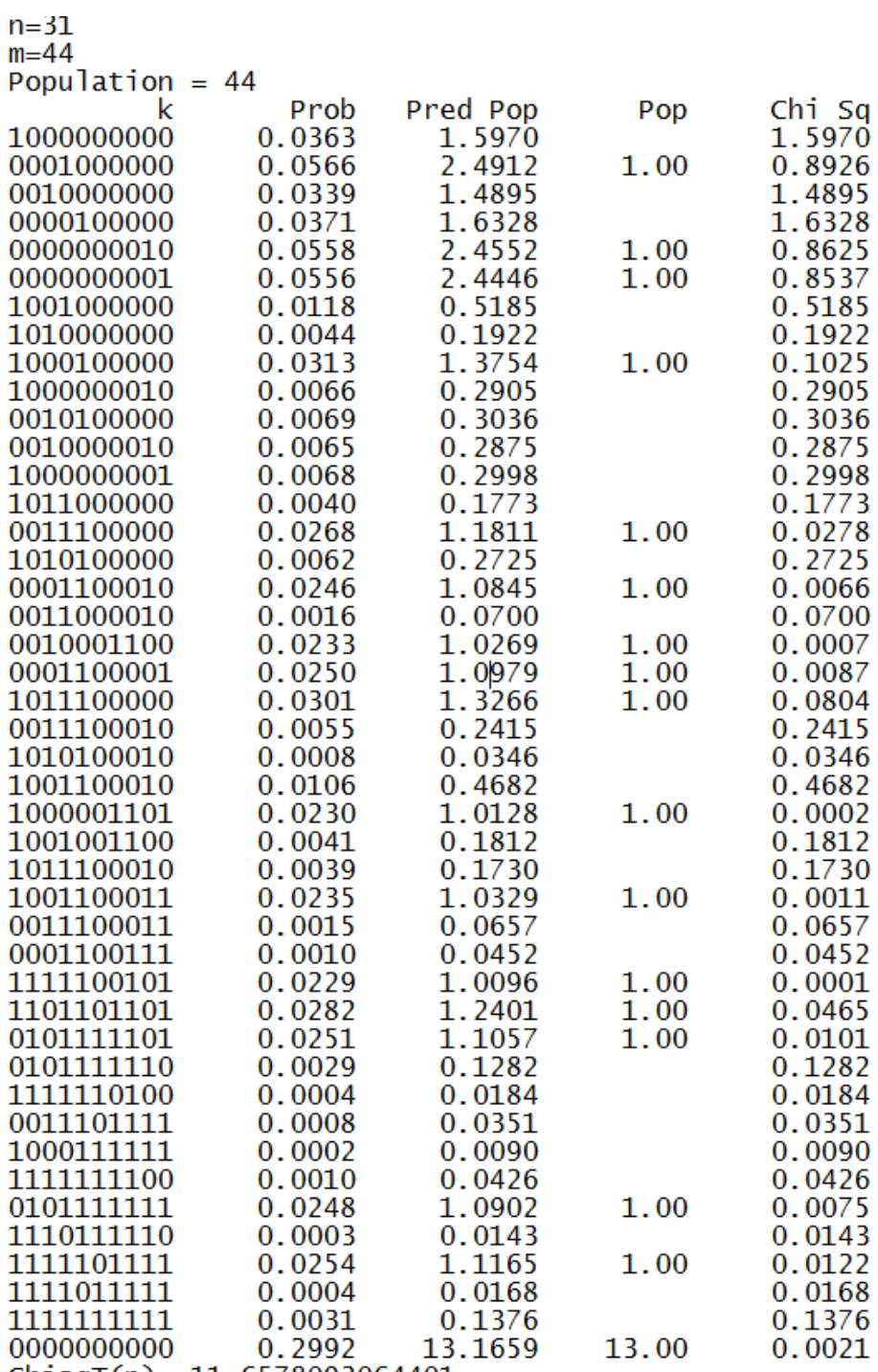

In Table $4, n$ is the number of initial response states, $m$ is the number of states in the assumed knowledge structure, and the population is 44 in the comparison group. The first column includes knowledge states for each student on questions 1 to 10, which similar to that of column 1 in Table 2. The second column represents the probability of the population in the given response state, and the third column is the predicted population in the assumed state. The fourth column represents the real population in a certain state while the last column is the $\chi^{2}$ value calculated from the real population and predicted population. The total $X^{2}$ value indicates whether the assumed knowledge structure fits the original response structure. In this case, the degree of freedom $(d f)$ can be defined as the summation of the number of knowledge states and the number of lucky-guess and careless errors minus 1 . In Table 3 , the degrees of freedom are given by the following equation: $\mathrm{df}=\mathrm{m}+10 \cdot 2-1=44+20-1=63$. Extracting the response state, predicted population, and real population from 
Table 3, we obtained either response state and real population or knowledge state and predicted population.

After loading skills function in the $\mathrm{R}$ package, a test on the response structure of the comparison group for Test 1 was conducted. A function called kspace() was used to create a knowledge space that includes one state for the empty set \{\} , one state for the full set of domain items, and a state for the union of any two knowledge states.

The knowledge structure (KS) for the experimental group (Test 1) was created by entering the following:

Ks

kstructure(set(set(1,2,3,4,5,7,8,9,10), set(1,2,3,4,5,7,9,10), set(2,4,5,6,7,8,9,10),set(1,2, $3,4,5,8,10)$,set $(1,2,4,5,7,8,10)$,set $(2,4,5,6,7,8,10)$, set $(1,2,4,5,7,8)$, set $(1,2,6,7,8,9)$,set $(1,4$, $5,6,7,8)$,set(1,4,5,7,8,10), set(2,3,4,5,7,8),set(1,4,5,9,10),set(1,4,7,8,9), set(3,4,5,7,10),set $(1,3,4,5), \operatorname{set}(1,7,8,10), \operatorname{set}(3,8,9,10), \operatorname{set}(4,5,7,8), \operatorname{set}(7,8,9,10), \operatorname{set}(1,4,5), \operatorname{set}(3,4,5), \operatorname{set}(3$, $7,8)$, set( $4,5,9), \operatorname{set}(4,5,10), \operatorname{set}(7,8,9)$, set(1,5),set(4),set(7), set(9),set(10)))

where kstructure is the function to create a knowledge structure and it is stored as $K s$. Next, the command $K s p \leftarrow \mathbf{k s p a c e}(K s)$ generates the knowledge space and store it as Ksp. Typing $t(\operatorname{convert}(K s p))$ shows the knowledge space structure in 0 and 1. In this case, the knowledge space structure is quite large, consisting of 151 knowledge states of the generated knowledge space.

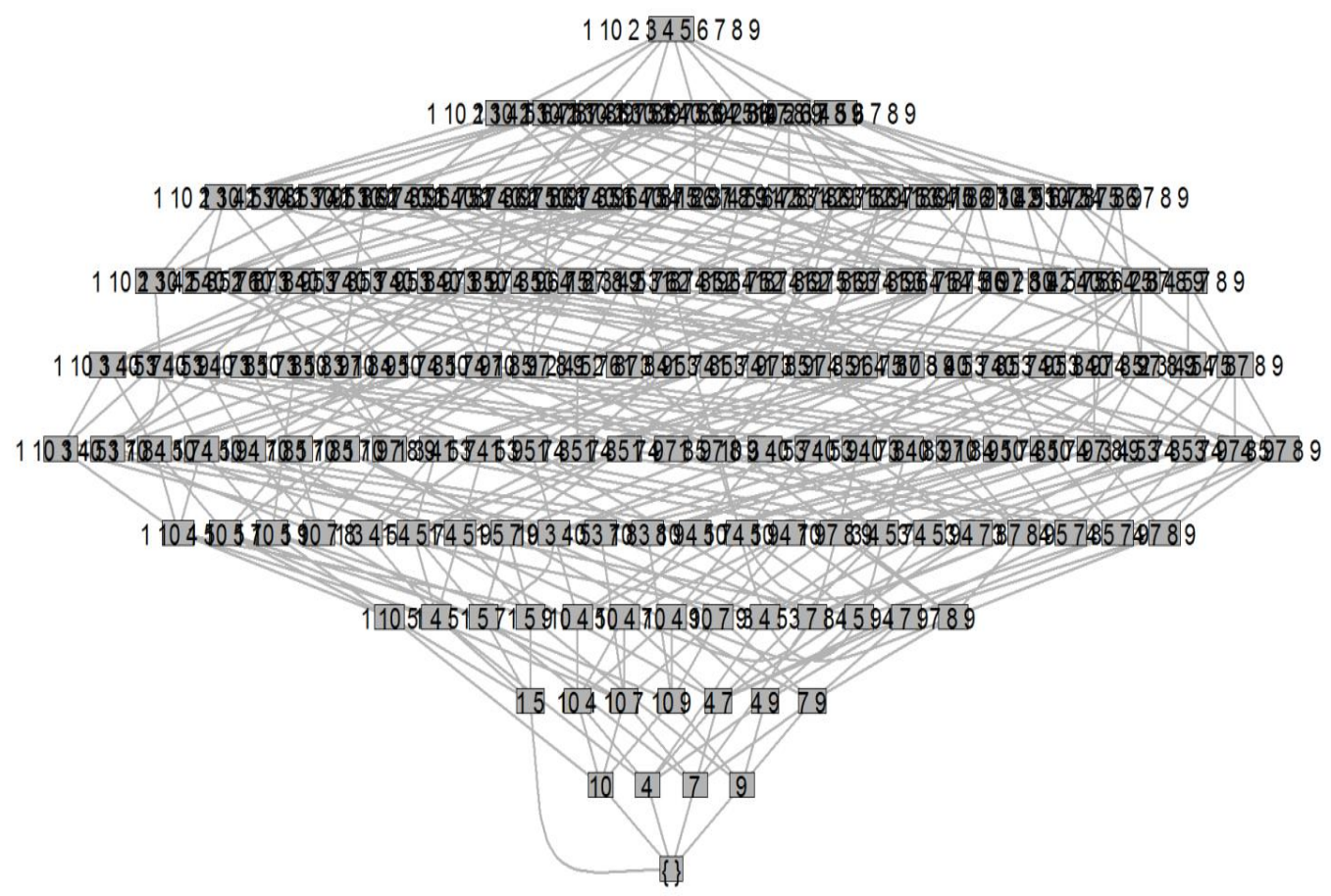

Figure 1: Knowledge states for Test 1 comparison group

Since the size of data is large for this test, the result of the plot is not decipherable. As a result, we were unable to determine the critical learning path based on the Figure depicted above. 
We also generated the knowledge structure for the experimental group for Test 2 in a similar way by typing the following code:

Ks $\leftarrow$ kstructure(set(set(1,2,3,4,5,6,7), $\operatorname{set}(1,2,3,4,5,6), \operatorname{set}(1,2,3,4,6,7), \operatorname{set}(1,2,3,5,6)$, $\operatorname{set}(2,3,5,6,7), \operatorname{set}(1,2,3,4), \operatorname{set}(1,2,4,6), \operatorname{set}(1,2,5,6), \operatorname{set}(1,2,6,7), \operatorname{set}(1,3,6,7), \operatorname{set}(1,2,6)$, $\operatorname{set}(1,3,6), \operatorname{set}(1,3,7), \operatorname{set}(2,5,6), \operatorname{set}(3,5,6), \operatorname{set}(1,6), \operatorname{set}(3,6), \operatorname{set}(4,6), \operatorname{set}(6,7), \operatorname{set}(6)))$

$\mathrm{Ksp} \leftarrow \operatorname{kspace}(K s)$.

Figure 2 shows the output Table and Figures $3 a \& 3 b$ depict the knowledge states and critical learning paths for Test 2 experimental group.

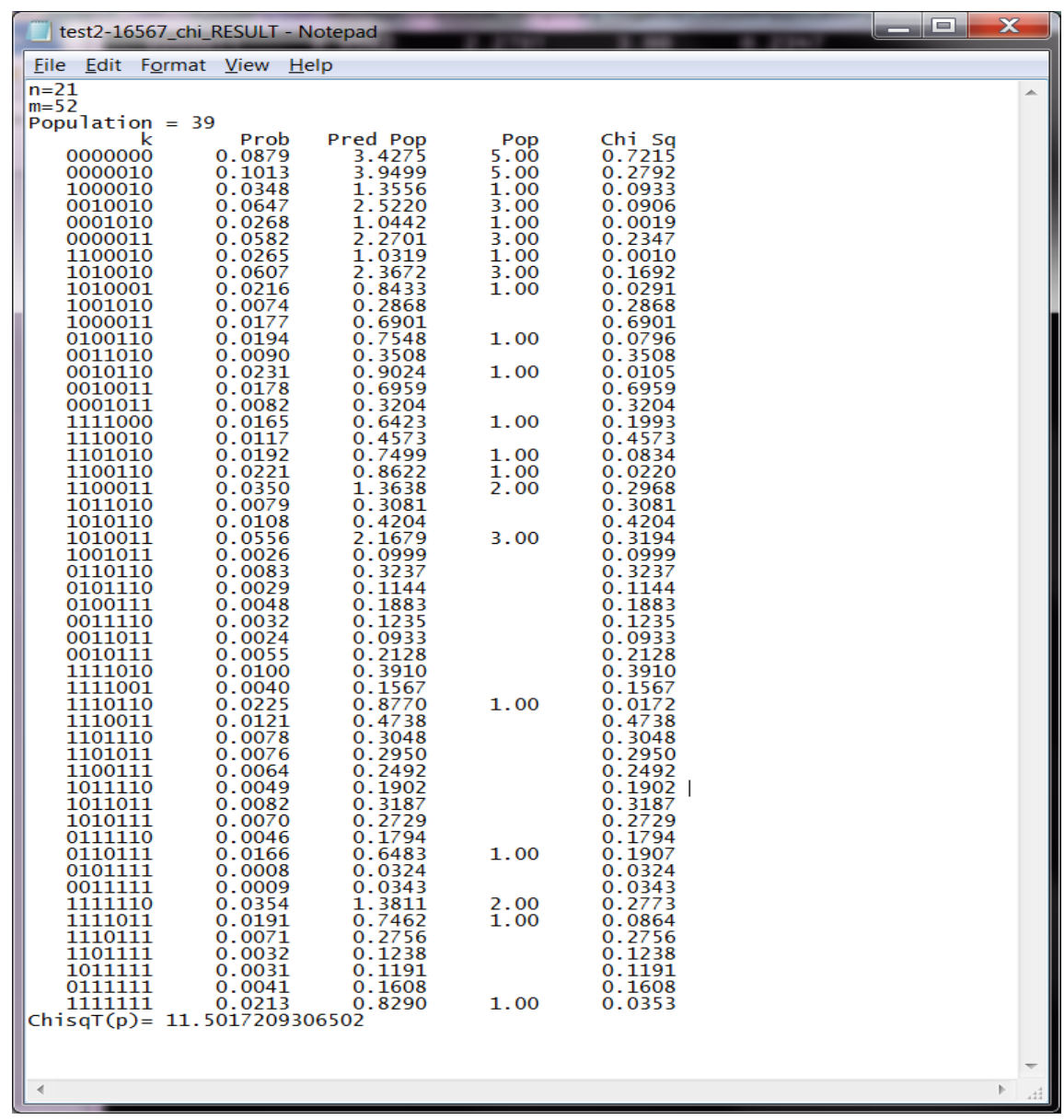

Figure 2: Output file for Test 2 experimental group

Furthermore, we show the knowledge structure of the experimental group in Test in Figure 3a. The number at the upper right corner of a box means the predicted population who can solve the items that are listed in the box. For instance, the number 0.83 denoted an exponent in 0.83 predicted students can solve questions 1 through 7 . The knowledge states in Figure 3a fit very well $(>99.9 \% ; \mathrm{p}<0.001)$ to the initial response states. 




Figure 3a: Knowledge states for Test 2 experimental group $\left(\chi^{2}=11.502 ; \mathrm{df}=65 ; \mathrm{p}<0.001\right.$; $>99.9 \%)$

When looking at the knowledge structure tree for the experimental group for Test 2, we noticed eight levels of knowledge states. The knowledge state at the bottom of the tree is considered the null set where nothing is answered correctly. The predicted population to obtain this outcome is indicated by the number above and to the right of this box. For the experimental group for Test 2, the predicted population is 3.43. The second level of the knowledge structure tree has one knowledge state with the number six in it. This number indicates that of all the students who correctly answered one question on the test, the highest frequency of correct responses was depicted for question six. The predicted population for this knowledge state is 3.95 students. The first edge of the learning path was created when these boxes were connected.

The third level of the knowledge structure tree had four different knowledge states. The learning path is connected to the knowledge state that has the highest predicted population and is connected to the previous knowledge state levels. Both of these conditions must be met to continue the critical learning path. If the box with the highest predicted population outcome is not connected to the knowledge state, then the second-highest connected knowledge state must be selected.

The fifth and sixth levels of the knowledge structure tree had fifteen and fourteen knowledge states respectively. This shows that the knowledge structure tree had greater variation and is not considered very organized. The total number of knowledge states for the entire knowledge structure tree is 52. Ideally the number of knowledge states should be less than the population of the class.

The seventh level of the knowledge structure tree had six different knowledge states. This shows that among the students who answered six out of the seven questions correctly, they are still experiencing greater variations with many 
different potential critical learning paths. The seventh level also has two knowledge states that are larger than the knowledge state selected for the critical learning path. The knowledge state just to the right of the selected knowledge state for the critical path has a predicted population of 0.88 . The knowledge state selected for the critical learning path is only 0.47 . On the seventh level, there is yet another knowledge state that had a larger predicted population than the knowledge state selected for the critical learning path. As mentioned previously, these two knowledge states with higher predicted population outcomes $(0.88$ and 0.65 ) are not connected to the previous level knowledge state. Therefore, the critical learning path cannot be connected to either of these higher predicted population knowledge states.

We also delineated the critical learning pathway for Test 2 experimental group that depicts the knowledge states with the highest populations (See Figure 3b).

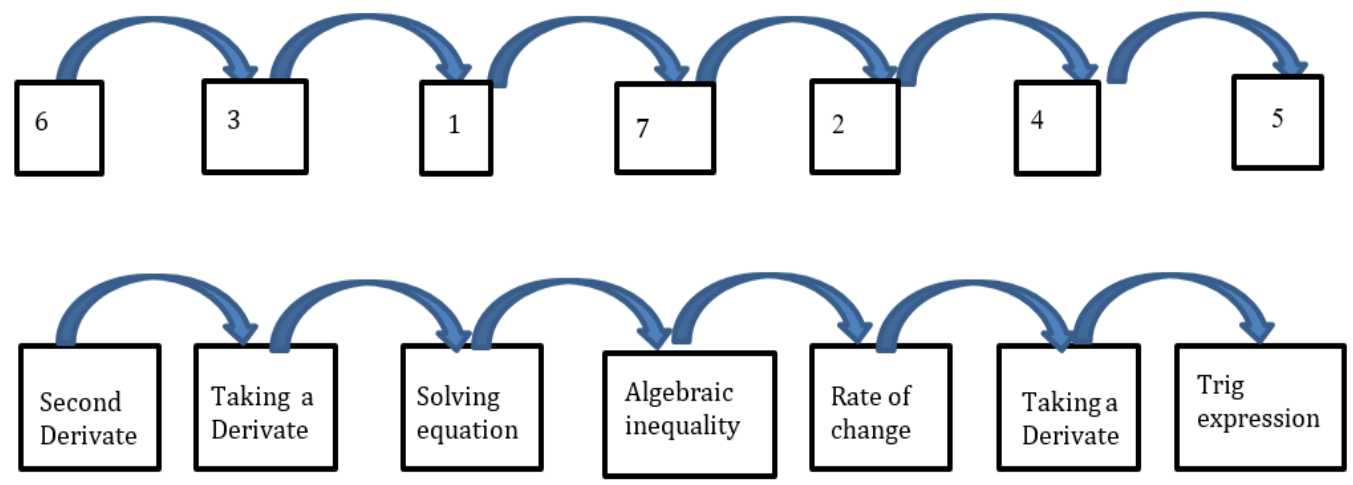

Figure 3b: Critical learning path for Test 2 experimental group

To determine the critical learning path, we selected the knowledge state with the highest population and fewest questions as the head of the critical learning path. Then, we identified the highest population superset of the selected head as the second set. By repeating the steps, all sets can be connected by the relationship between the subsets and the supersets. The critical learning pathway can be determined by these selected sets. For instance, the critical learning path of Test 2 for the experimental group is $6 \rightarrow 3 \rightarrow 1 \rightarrow 7 \rightarrow 2 \rightarrow 4 \rightarrow 5$ (Figure $3 b$ ). The questions that are related to this critical learning path are: taking a second derivative (Calculus) $\rightarrow$ taking a derivative (Calculus) $\rightarrow$ solving simple equations for one of the variables (Precalculus) $\rightarrow$ solving an algebraic inequality (Precalculus) $\rightarrow$ finding the rate of change as the derivative (Calculus) $\rightarrow$ taking a derivative (Calculus) $\rightarrow$ evaluating a trigonometric expression (Precalculus).

For the comparison group, the knowledge states and critical learning paths were extracted as shown in Figures $4 \mathrm{a} \& 4 \mathrm{~b}$. The knowledge structure tree showed traits of disorganization similar to the knowledge structure tree found for the experimental group. The fourth, fifth, and sixth levels have large numbers of knowledge states. There was a total of thirty knowledge states on these three levels accounting for 61 percent of all knowledge states, which provided evidence that the knowledge structure tree is also not very organized. The total number of knowledge states, forty-four, greatly exceeded the population of the 
class. On the sixth level of the knowledge structure tree, there was a knowledge state that had a higher predicted population outcome than the knowledge state selected for the critical learning path. This result was expected since the fifth level knowledge state was not connected to this higher knowledge state on the sixth level as previously explained.

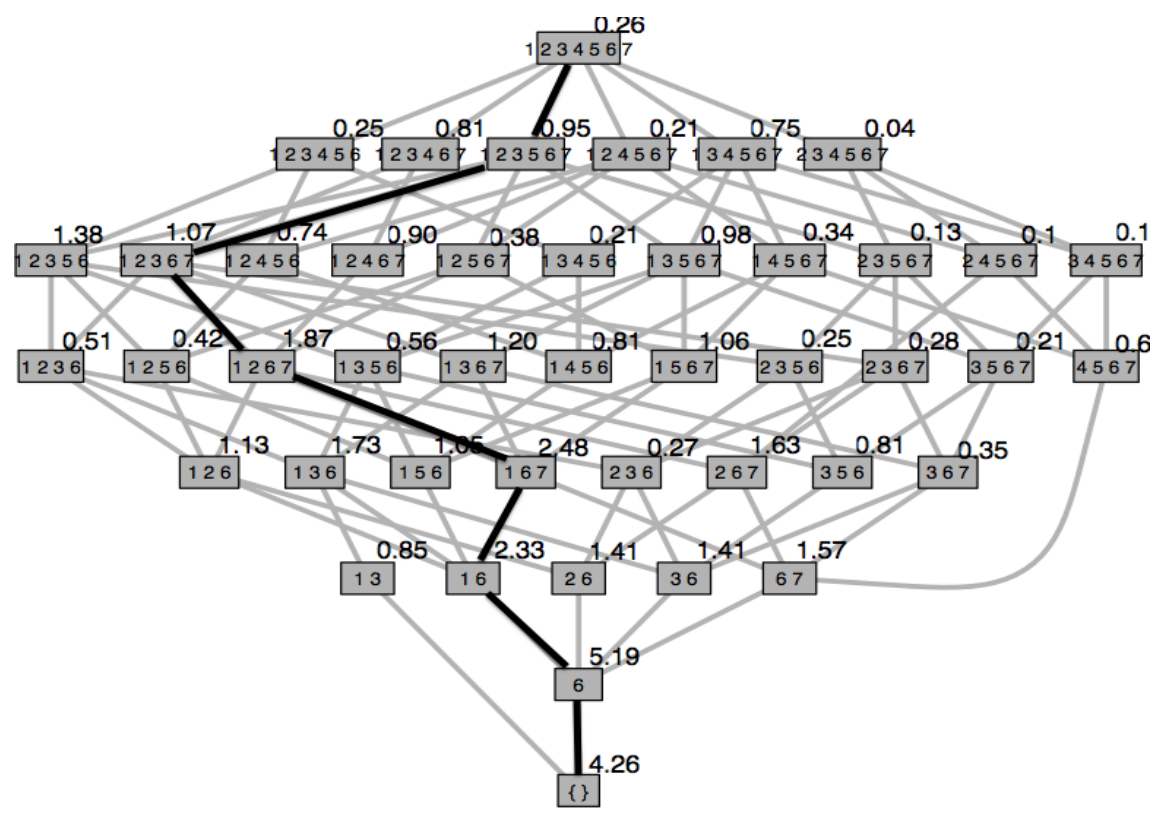

Figure 4a: Knowledge states for test 2 comparison group $\left(\chi^{2}=7.78 ; \mathrm{df}=57 ; \mathrm{p}<0.001\right.$; $>99.9 \%$ )

To delineate the learning path, we noted the following trajectory: $6 \rightarrow 1 \rightarrow 7 \rightarrow 2$ $\rightarrow 3 \rightarrow 5 \rightarrow 4$ corresponding to the question items: taking a second derivative (Calculus) $\rightarrow$ solving simple equations for one of the variables (Precalculus) $\rightarrow$ solving an algebraic inequality (Precalculus) $\rightarrow$ finding the rate of change as the derivative (Calculus) $\rightarrow$ taking a derivative (Calculus) $\rightarrow$ evaluating a trigonometric expression (Precalculus) $\rightarrow$ taking a derivative (Calculus) (See Figure $4 b$ ).

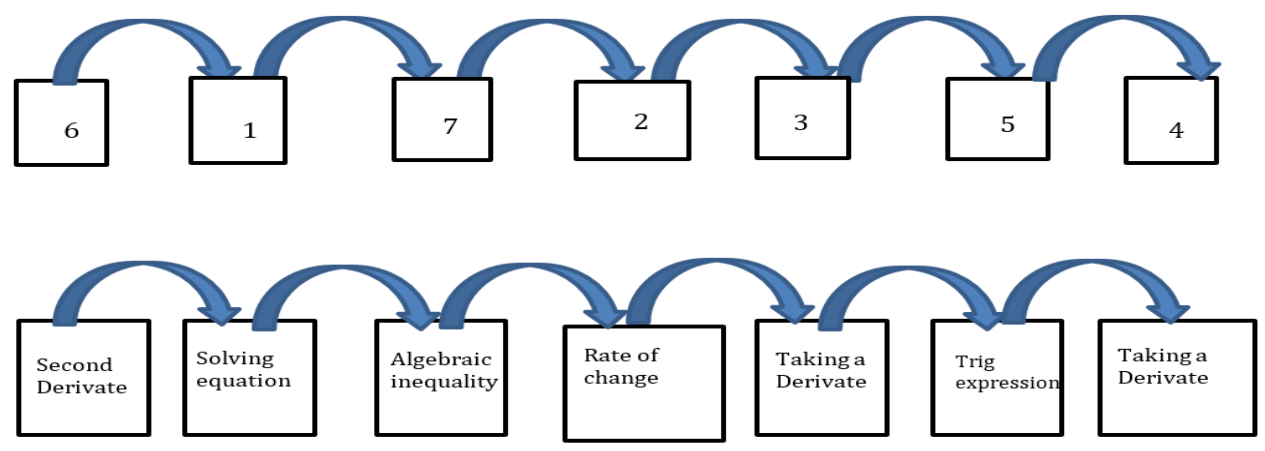

Figure 4b: Critical learning path for Test 2 comparison group

It was obvious that the path for the experimental group is different, with the main difference being the order of question 3, which is related to taking a derivative. Question 4, which is also about the derivative, is considered as a difficult question for both groups. Test 2 for the comparison group contains only 
26 knowledge states (Figure 4a), which is simpler than that of the experimental group. Simpler knowledge structures in the comparison group indicate betterorganized knowledge (Arasasingham et al., 2005). However, we only can assume that different groups may have different levels of understanding of the calculus of taking derivatives.

For Test 4, we used the same process to generate the output of knowledge states and to create the knowledge structure for the experimental (Figure 5a) and comparison groups (Figure 6a). We found the critical learning path of Test 4 for the experimental group (Figure $5 b$ ) to be: $1 \rightarrow 2 \rightarrow 5 \rightarrow 3 \rightarrow 4 \rightarrow 6$, which is: solving algebraic inequalities (Precalculus) and finding the velocity and the acceleration as derivatives (Calculus) $\rightarrow$ sketching two graphs and the region between them and finding their points of intersections (Precalculus) $\rightarrow$ finding an antiderivative (Calculus) $\rightarrow$ evaluating antiderivative (Precalculus) $\rightarrow$ integrating to find the area (Calculus).

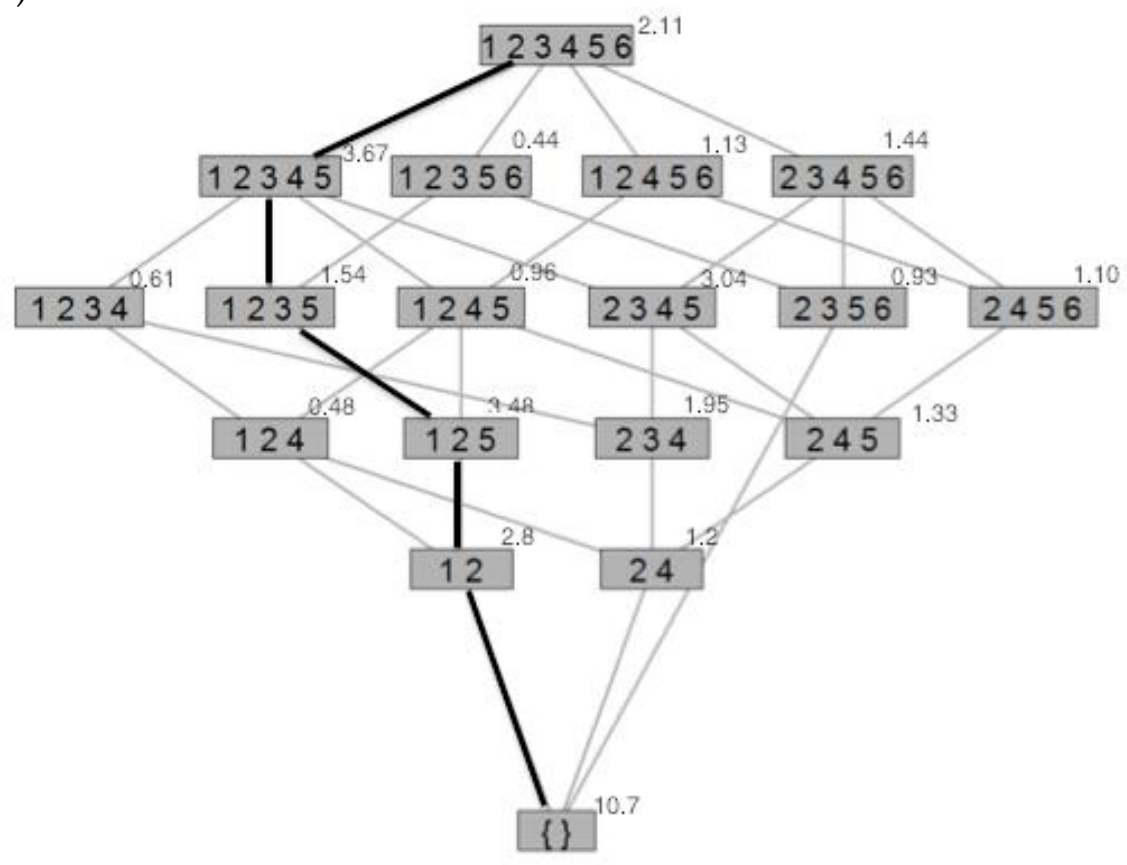

Figure 5a: knowledge states for Test 4 experimental group $\left(\chi^{2}=4.067 ; f=29 ; p<0.001 ;>\right.$ $99.9 \%)$

A close comparative examination of the knowledge structure trees for Test 4 in the experimental group revealed the greatest organization of all four of the knowledge structure trees that emerged for both groups. There were only six total levels because none of the students correctly answered only one question on the test. Therefore, the second level of the knowledge structure tree effectively did not exist. We considered this knowledge structure tree to be more organized because it has a total of only 18 knowledge states. This number is considerably closer to the class population than the previous knowledge structure trees. Furthermore, the critical learning path for this knowledge structure tree (See Figure $5 b$ ) passed through the highest predicted population 
outcomes for each knowledge state at each level, showing a more direct learning path from the null set at the bottom to the complete set at the top.

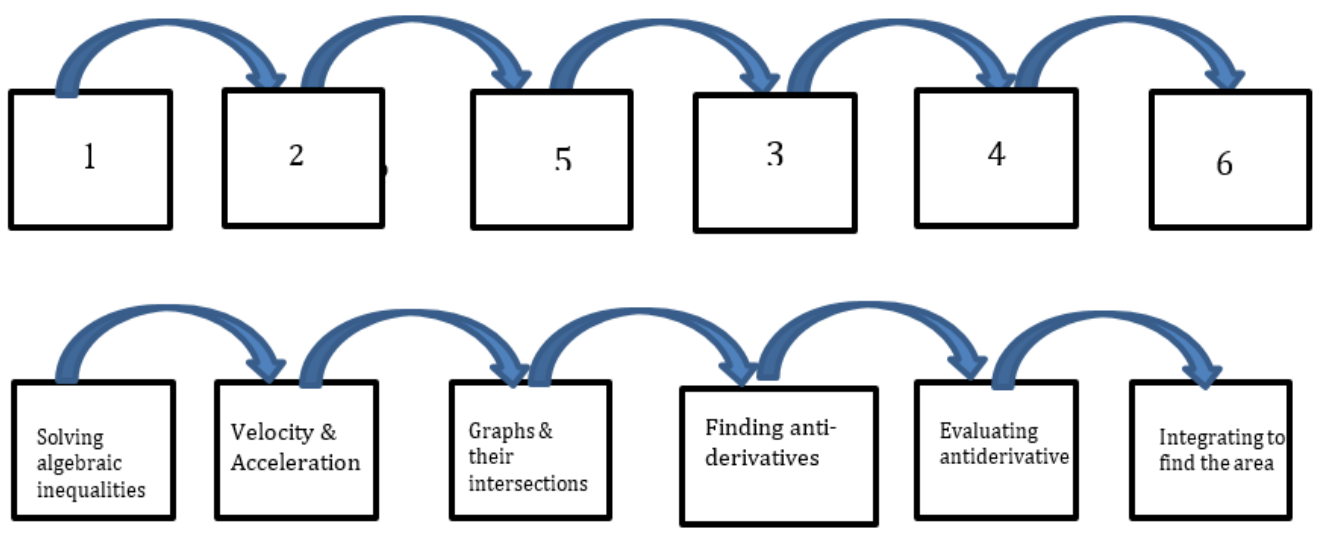

Figure 5b: Critical learning path for Test 4 experimental group

Similarly, the knowledge structure tree for the comparison group on Test 4 also showed better organization than the two knowledge structure trees from Test 2 (See Figure 6a). The knowledge structure tree had seven levels and thirty knowledge states. The fourth and fifth levels of the knowledge state tree contained the majority of the knowledge states with about fifty-seven percent of the knowledge states occurring on these levels.

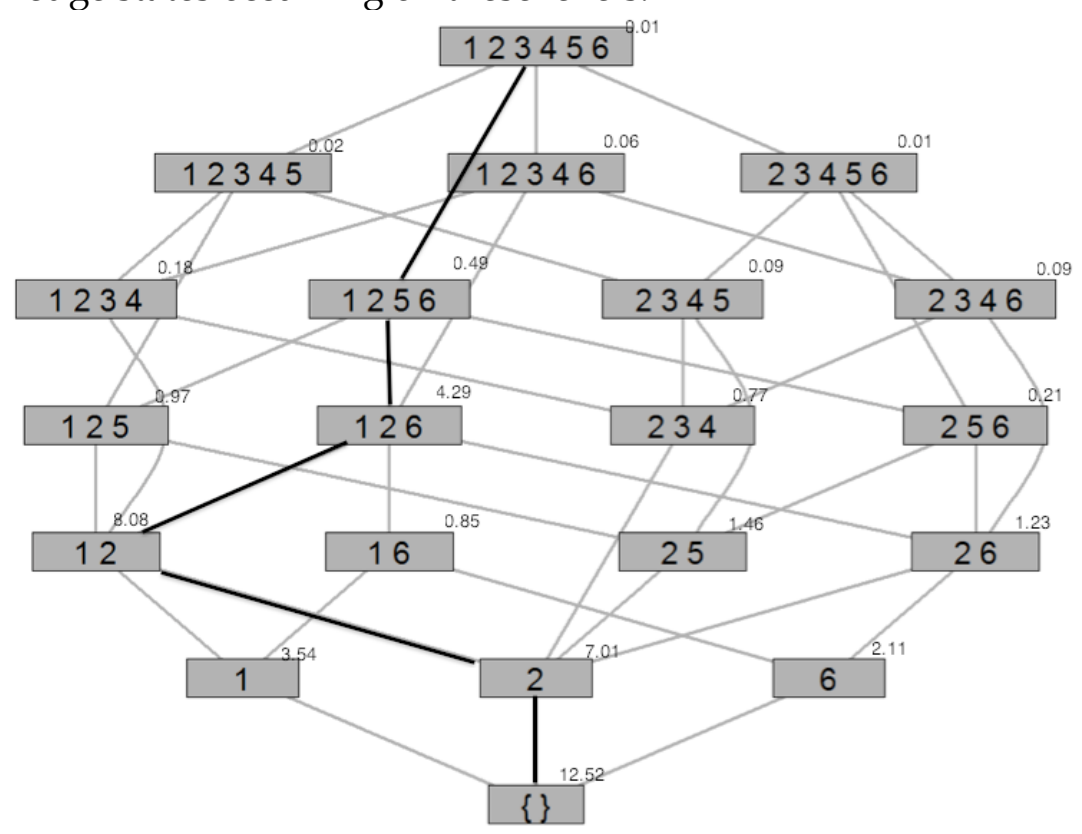

Figure 6a: knowledge states for Test 4 comparison group $\left(\chi^{2}=7.846 ; \mathrm{df}=31 ; \mathrm{p}<0.001 ;>\right.$ 99.9\%)

The critical learning path also passed through each of the highest predicted population knowledge states for each level (See Figure 6b). 


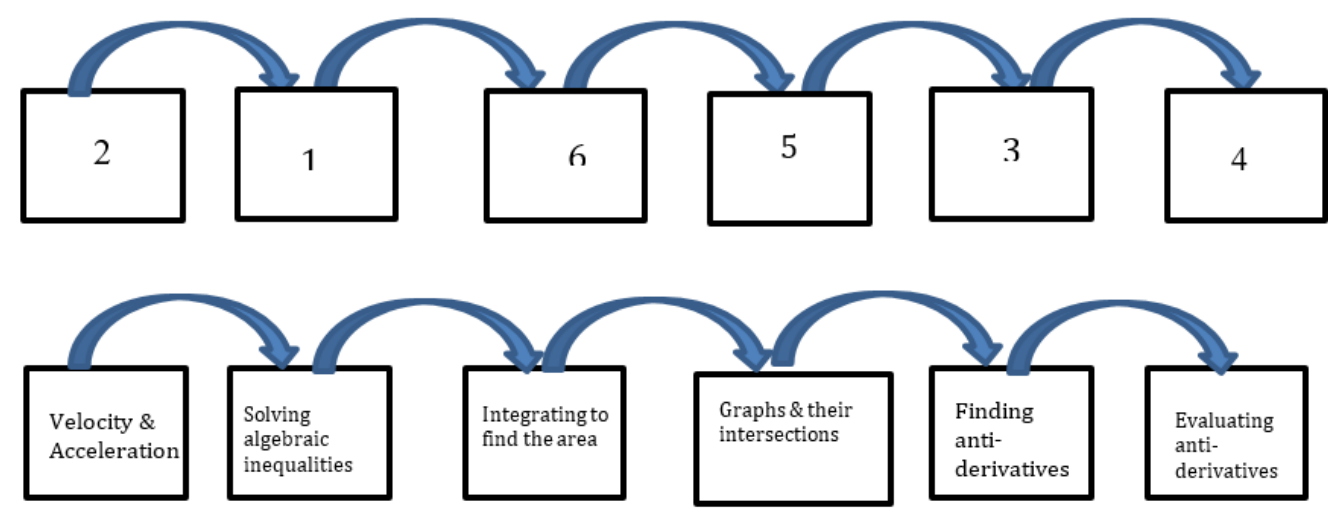

Figure 6b: Critical learning path for Test 4 comparison group

This pattern of critical learning path is also different for the comparison group for Test 4 , which is: $2 \rightarrow 1 \rightarrow 6 \rightarrow 5 \rightarrow 3 \rightarrow 4$ (Figure $6 \mathrm{~b}$ ). The corresponding questions are: solving algebraic inequalities (Precalculus) $\rightarrow$ finding the velocity and the acceleration as derivatives (Calculus) $\rightarrow$ integrating to find the area (Calculus) $\rightarrow$ sketching two graphs and the region between them and finding their points of intersections (Precalculus) $\rightarrow$ finding an antiderivative (Calculus) and evaluating antiderivative (Precalculus). The major difference in the critical learning pathways between the comparison and experimental groups is the order of question 6 . We concluded, in this case, that the experimental group did not fully comprehend the integration concept.

Similarly, we performed the analysis for the final exam, which had a total of 14 questions, 6 of which are related to Precalculus concepts. We generated the output of knowledge states and created the knowledge structure for the experimental (Figure 7a) and comparison group (Figure 8a). For the final exam in the experimental group, the critical learning path that emerged is $6 \rightarrow 4 \rightarrow 2$ $\rightarrow 5 \rightarrow 1 \rightarrow 3$ (Figure $7 \mathrm{~b}$ ) and the related topics were: sketching and finding the area $\rightarrow$ finding the domain and intercepts $\rightarrow$ evaluating to find the limits $\rightarrow$ taking a derivative $\rightarrow$ finding maximum value $\rightarrow$ evaluating to find limits.

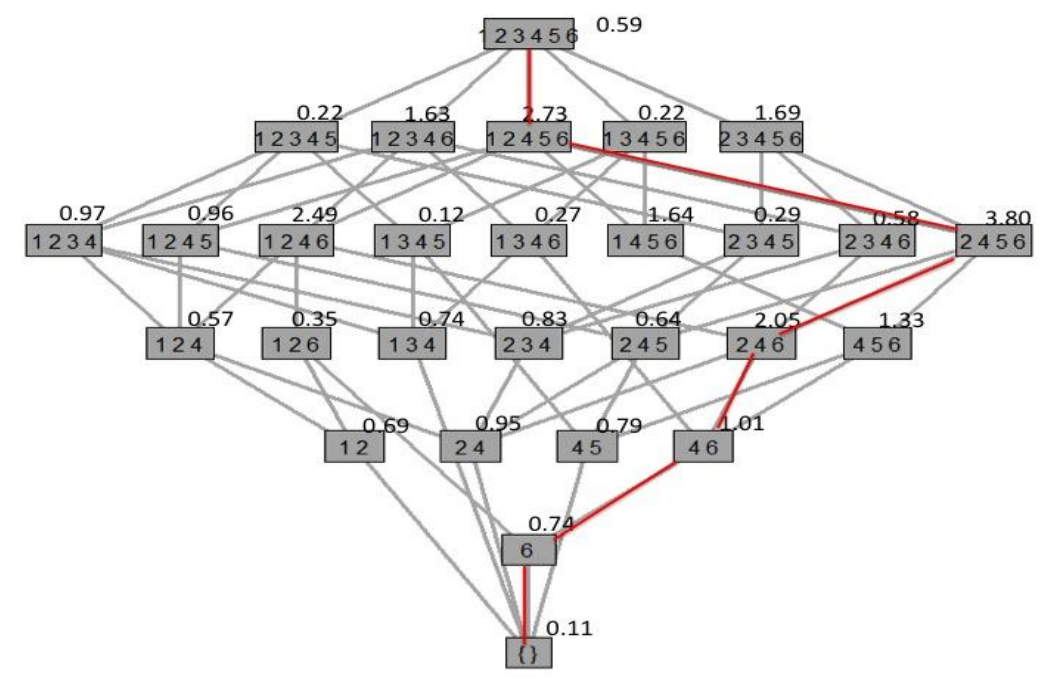

Figure 7a: knowledge states for final exam experimental group 


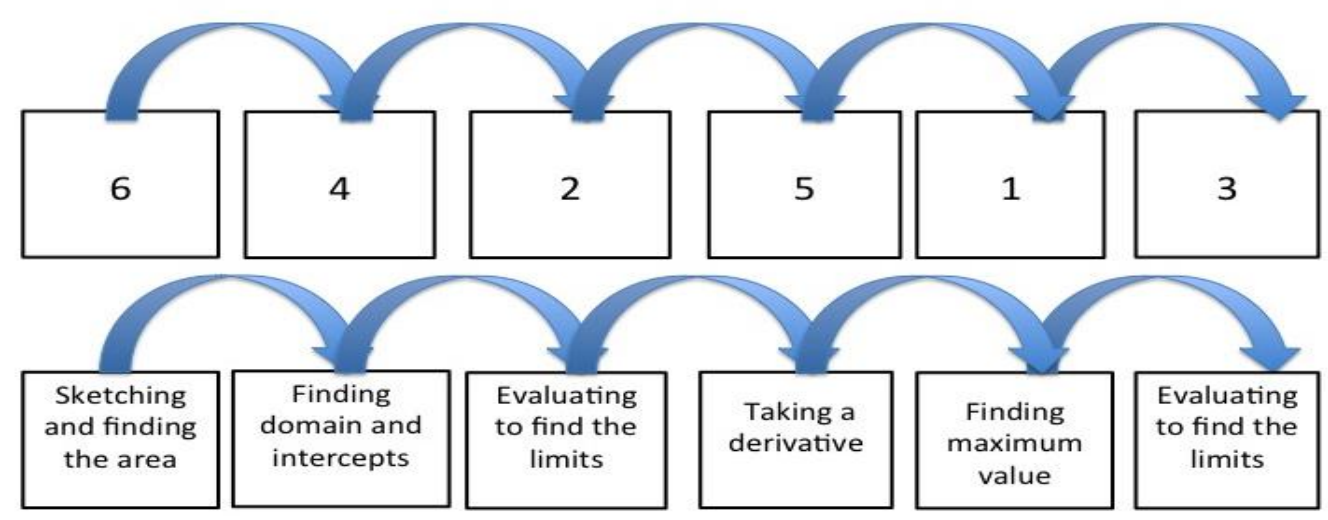

Figure 7b: Critical learning path for final exam experimental group

The critical learning path for the comparison group was found to be 4,6 $\rightarrow 2 \rightarrow 5 \rightarrow 3 \rightarrow 1$, and the related topics were: finding domain and intercepts and sketching and finding the area $\rightarrow$ evaluating to find the limits $\rightarrow$ taking a derivative $\rightarrow$ evaluating to find limits $\rightarrow$ finding maximum value (Figure $8 \mathrm{~b}$ ).

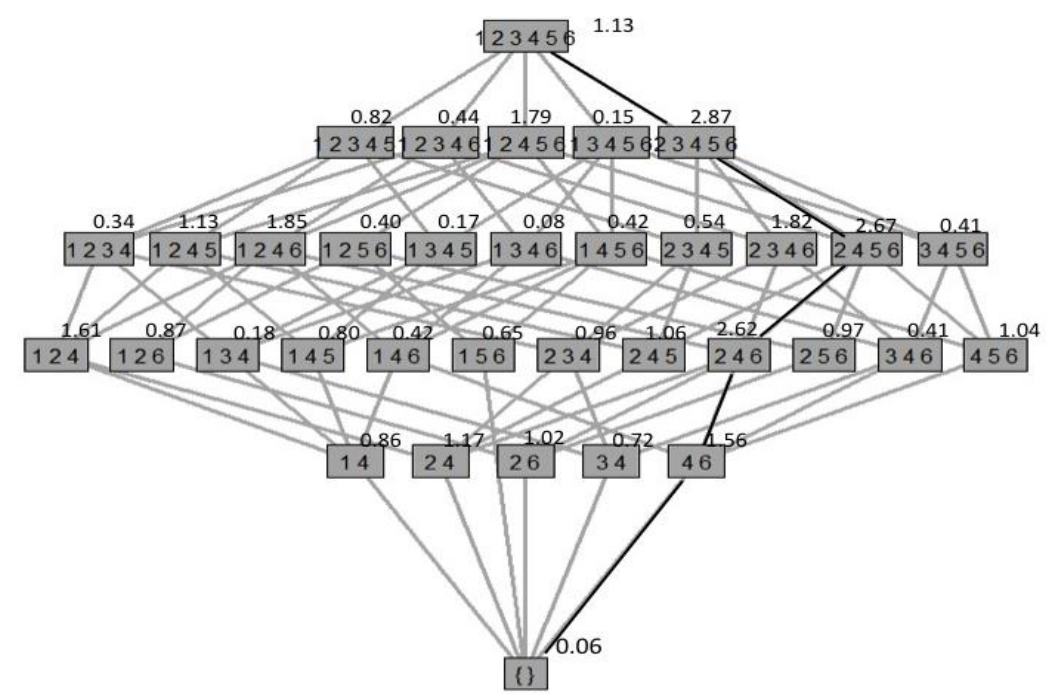

Figure 8a: Knowledge states for final exam comparison group
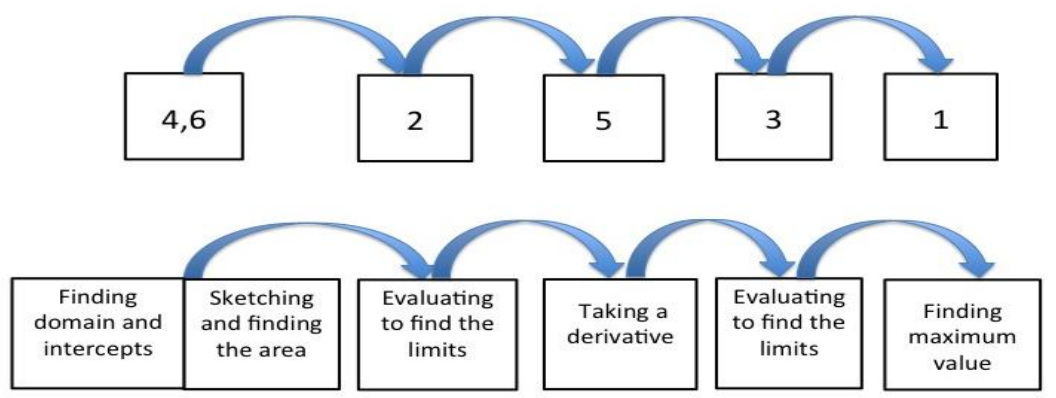

Figure 8b: Critical learning path for final exam comparison group 


\section{Findings and Discussion}

Overall, this study showed that the knowledge structures of the comparison group were less complex than those of the experimental group, which indicates that the knowledge states of the comparison group are more organized. Based on the degrees of freedom, the levels of knowledge organization for both groups were similar in Test 4 . We also found that different groups have different understanding levels on the derivative questions. For the experimental group, perhaps the teacher needed to spend more time explaining how to solve advanced derivative questions, even though students understood how to solve relatively simpler ones. The performance of the experimental group also indicated that integration problems are more difficult to complete.

When we implemented the knowledge structure theory in our first assessment, the test consisted of 10 questions. The possibility of a large number of subsets led to a knowledge structure tree that was too difficult to follow; consequently, it was not an easy task to determine a critical learning path (see Figure 2). After this first attempt, we implemented the knowledge structure theory for two shorter assessments. Test 2 was given within the first six weeks of the class. And although the knowledge structure trees on Test 2 already differed between the comparison and the experimental groups, it is in Test 4 that knowledge structure trees showed a greater change in the critical learning paths, thereby indicating a more developed understanding of concepts.

When comparing the total knowledge states for Test 2, we detected eight more knowledge states in the comparison group than in the experimental group; and for Test 4 there were twelve more knowledge states for the comparison group. The experimental group also had a large reduction in the number of knowledge states from the second test to the first test. The number of knowledge states for Test 2 was 52, but for Test 4 there were only eighteen. This is a decrease of 61 percent. The comparison group, on the other hand, had a smaller reduction in the number of knowledge states going from 42 in Test 2 to 30 in Test 4 . This is a decrease of only 31 percent.

Our results for Test 2 showed that the experimental group, which received extra instruction in Precalculus concepts weekly, completed question 3, finding derivatives much sooner than the comparison group. The experimental groups' critical learning path showed that the class had a better understanding of completing the first derivative and second derivative questions. We hypothesized that the comparison group only memorized the method for taking the second derivative and that is why their critical learning path has a substantial number of questions between the two derivative questions. It only makes sense that taking the derivate (question 3) and then taking the second derivative (question 6) should be next to each other on the critical learning path, not at either end in reverse order.

Additionally, the knowledge structure tree diagrams for Test $2 \&$ Test 4 revealed that both experimental and comparison classes did very well on concepts taught immediately before the test. For example, question 5 was first on the critical 
learning path for the comparison group and second on the critical learning path for the experimental group. Question 5 asked students to sketch the region bounded between two given curves and to find their points of intersection. This concept, according to the course syllabus, was taught immediately before administering Test 4 . Both classes received instruction on how to take the second derivate just before the assessment. The critical learning path for both classes started with question six in which students were asked to find the second derivate. The knowledge structure tree critical learning path for the experimental group also revealed that students completed the calculus questions sooner on the critical learning path than the comparison class. Moreover, the experimental groups' critical learning path had questions four and five correctly ordered. To complete question five correctly on the critical learning path, students needed to answer question four accurately. And while the experimental group navigated these two questions in the correct order, the comparison group answered these two questions in reverse order. This result may mean that the comparison group was either guessing here or had several concepts confused. Therefore, students were not able to correctly apply the concepts to systematically solve the trigonometry application portion of the question.

Furthermore, Test 4 critical learning path for the experimental group showed that the class was very successful in completing questions 1 and 2. These two questions involved finding the derivate and then using the results from question 1 to solve the algebraic inequality for question 2. The experimental groups' critical learning path also revealed that students completed questions 3 and 4 in the correct order. To correctly complete question 4 , students first had to correctly solve question 3, which involved finding an antiderivative and then question 4 was evaluating the antiderivative. For the comparison group, on the other hand, the critical learning path for Test 4 indicated that students were neither able to find the derivate or anti-derivate nor apply it correctly. Questions 1 and 2 on the critical learning path were not only in reverse order but they were also separated by question 3 . The comparison group completed questions 3 and 4 in the correct order, but they were separated on the critical learning path by question 1 .

It was interesting to note that the comparison group continued to have greater difficulty taking the derivate on Test 4 than the experimental group. This supported our assumption that the comparison class might have been memorizing how to take the derivate and not learning the concepts meaningfully. As the calculus course progressed through the semester, the comparison group's critical learning path continued to depict derivative and application questions in a reversed manner.

\section{Conclusion}

In this study, we showed that an employment of knowledge space theory provided an efficient procedure to represent the structure of a group of students' domain of knowledge in calculus. Such methodology was meaningful in formatively assessing students' skills and knowledge, which provided useful insight into potential remediation needed to improve students' performance. 
Overall, critical learning paths supported the conclusion that a strong foundation in Precalculus is necessary for students' success in Calculus and beyond. Juxtaposing the succession of knowledge states and critical learning paths reflected student understanding of the basic calculus concepts and proposed a systematic approach to supplemental enrichment and remediation.

It is the intention of this study to champion the use of KST approaches as a means to assess student learning across diverse disciplines and at all school levels. We argue that an investigation of the critical learning paths of different assessment strategies would give instructors the ability to generate knowledge structure trees that depict student acquisition of concepts, to provide guidelines for instructors to adjust the order of the concepts taught, and to potentially customize the instruction based on the expected mastery level.

While improving STEM education in the U.S. has been a critical national concern, the pipeline of students entering STEM does not meet the current demand for future scientists and engineers (Carlson, Oehrtman, \& Engelke, 2010). One of the reasons identified for this attrition has been students' underperformance in calculus and their inadequate preparation in Precalculus content. Hence, addressing this national need requires the development of pathways to remediate the teaching of such concepts, which would translate into efficient models for supporting meaningful learning. It is our conviction that evidence-based approaches driven by conceptually designed models such as KST can positively contribute to student retention and their future success in Calculus courses and beyond.

\section{References}

Arasasingham, R. D., Taagepera, M., Potter, F., Martorell, I., \& Lonjers, S. (2005). Assessing the effect of web-based learning tools on student understanding of Stoichiometry using knowledge space theory. Journal of Chemical Education, 82(8), 1251.

Berkaliev, Z. \& Kloosterman, P. (2009). Undergraduate engineering majors' beliefs about mathematics. School Science and Mathematics, 109,175-182.

Bishop-Clark, C., Hurn, J., Perry, S., Freeman, M., Jernigan, M., Wright, F., \& Weldy, N. (2010). High school teachers teaching college courses to career technical education students: A story of success. Journal of Career and Technical Education, 25(2), 78-93.

Bonne, L., \& Johnston, M. (2016). Students' beliefs about themselves as mathematics learners. Thinking Skills and Creativity, 20, 17- 28.

Bressoud, D. M., Carlson, M.P., Mesa, V., \& Rasmussen, C. (2013). The calculus students: Insights from the Mathematical Association of America national study, International Journal of Mathematica Education in Science and Technology, 44(5), 685698. https:/ / doi.org/10.1080/0020739X.2013.798874

Cardetti, F., \& McKenna, P. J. (2011). In their own words: Getting pumped for Calculus. Primus, 21(4), 351-363.

Carlson, M., Oehrtman, M., \& Engelke, N. (2010). The Precalculus Concept Assessment: A tool for assessing students' reasoning abilities and understanding, Cognition and Instruction 28(2), 113-145

Crouch, R., \& Haines, C. (2004). Mathematical modeling: Transitions between the real world and the mathematical world. International Journal on Mathematics Education 
in Science and Technology, 35(2), 197-206.

Doignon, J., \& Falmagne, J. (2015). Knowledge spaces and learning spaces. Retrieved from

https://www.researchgate.net/publication/284579542_Knowledge_Spaces_and _Learning_Spaces

Falmagne, J., Koppen, M., Villano, M., Doignon, J., \& Johannesen, L. (1990). Introduction to knowledge spaces: How to build, test, and search them. Psychological Review, 97(2), 201-224. DOI:10.1037/0033-295X.97.2.201

Ganter, S. L. (2001). Changing calculus: A report on evaluation efforts and national impact from 1988 to 1998 (Vol. 56). Washington, DC: Mathematical Association of America.

Ganter, S. L., \& Haver, W. E. (2011). Partner discipline recommendations for introductory college mathematics and the implications for college algebra. Washington, DC: Mathematical Association of America.

Karaali, G. (2011). An evaluative Calculus project: Applying Bloom's Taxonomy to the Calculus classroom. Primus, 21(8), 719-731.

Kay, R., \& Kletskin, I. (2010). Evaluating the use of learning objects for improving Calculus readiness. Journal of Computers in Mathematics And Science Teaching, 29(1), 87-104.

Kena, G., Musu-Gillette, L., Robinson, J., Wang, X., Rathbun, A., Zhang, J., WilkinsonFlicker, S., Barmer, A., \& Dunlop Velez, E. (2015). The Condition of Education 2015 (NCES 2015-144). U.S. Department of Education, National Center for Education Statistics. Washington, DC. Retrieved [date] from http://nces.ed.gov/pubsearch

Klymchuk, S., Zverkova, T., Gruenwald, N., \& Sauerbier, G. (2010). University students' difficulties in solving application problems in Calculus: Student perspectives. Mathematics Education Research Journal, 22(2), 81-91.

Naidoo, K., \& Naidoo, R. (2007). First-year students' understanding of elementary concepts in differential calculus in a computer teaching environment. Journal of College Teaching and Learning, 4(8), 99-114.

National Science Board. (2018a). Science and engineering indicators 2018. Retrieved from https://www.nsf.gov/statistics/2018/nsb20181/

National Science Board. (2018b). Higher education in science and engineering report. Retrieved from https://www.nsf.gov/statistics/2018/nsb20181/report

National Science Foundation. (NSF) (2018). S EE degrees: 2000-2017. Retrieved from https://nsf.gov/statistics/2018/nsb20181/report/sections/higher-educationin-science-and-engineering/ undergraduate-education-enrollment-and-degreesin-the-united-states

National Science Foundation. (NSF) (2018). Women, minorities, and persons with disabilities in science and engineering. Retrieved from https://ncses.nsf.gov/pubs/nsf19304/data

Pilgrim, M. E. (2010). A concept for calculus intervention: Measuring student attitudes toward mathematics and achievement in calculus (Unpublished Doctoral dissertation). Colorado State University, Colorado.

Rajagukguk, W. (2016). Some factors affected student's calculus learning outcomes. Journal of Education and Practice, 7(13), 96-105.

Reinholz, D. L. (2009). An analysis of factors affecting student success in math 160 calculus for physical scientists. (Thesis submitted for Master of Science). Colorado State University, Fort Collins.

Sanghoon, L., Belkasim, S., Chahine, I. C., \& Grinshpon, M. (2014). A web application for the Knowledge Space Theory analysis: KST Web. International Journal of Engineering Research \& Technology (IJERT), 3(9). ISSN: 2278-0181. 
Snyder, T. D., \& Dillow, S. A. (2010). Digest of Education Statistics 2009 (NCES 2010-013). National Center for Education Statistics, Institute of Education Sciences, U.S. Department of Education. Washington, DC.

Spoto, A., Stefanutti, L., \& Vidotto, G. (2010). Knowledge space theory, formal concept analysis, and computerized psychological assessment. Behavior Research Methods, $42,342-350$.

Stahl, C., \& Hockemeyer, C. (2019). Knowledge space theory. Retrieved from https://cran.r-project.org/web/packages/kst/vignettes/kst.pdf

Steiner, C. M., Nussbaumer, A., \& Albert, D. (2009). Supporting self-regulated personalized learning through competence-based Knowledge Space Theory. Policy Futures in Education, 7(6), 645-661.

Tóth, Z., \& Ludányi, L. (2007). Using phenomenography combined with knowledge space theory to study students' thinking patterns in describing an atom. Journal of Chemistry Education Research and Practice, 8, 327-336. 